\title{
Perceptive Gap among Interest Groups to Significance of the Installation Standards of Churches' Convenience Facilities for the Elderly
}

\author{
고령자를 위한 교회 편의시설 설치기준의 중요도에 대한 주체별 인식의 간극 \\ Lee, Jong-Hee* 이종희 | Kim, Duk-Su** 김덕수
}

\begin{abstract}
Purpose: The purpose of this study is to provide reference points for the improvement work of churches' convenience facilities for the elderly. To do this, the study generates survey results, showing that the perception to significance of churches' convenience facilities is different among survey constituents. Method: The survey method was utilized. The study population for survey includes the aged believer over 65 years old, pastors, and architecture and/or interior design experts. The questionnaire was devised while consulting existing regulations regarding convenience facilities in general. Results: It is found that the perception to significance of installation standards for convenience facilities is different among survey constituents. Specifically, while the older believer group is perceived that installation standards for the small group meeting room of 'other facility' is comparatively more important, the pastor group and the expert group perceive that the 'intermediate facility' and 'inner facility' are more important. Implications: Participants involved in an improvement project of churches' convenience facilities may have a different perception about their importance due mainly to the degree of usage and the difference of perspectives. This study, therefore, can be used as a reference point for prioritizing improvement works of churches' convenience facilities for the elderly.
\end{abstract}

Keywords Churches' convenience facilities, Installation standards, Convenience facilities for the elderly.

주 제 어교회편의시설, 설치기준, 고령자편의시설

\section{Introduction}

\subsection{Background and Objective}

한국 인구구조의 고령화 현상과 연동하여 교회 신도 중 고령신도의 비율이 증가하고 있다. 고령자의 신체 및 인지 능력의 저하에 대응하는 물리적 환경의 변경요구가 발생하 고 있다. 이용 편의성을 증진시키기 위해서는 고령신도의 요구사항 파악뿐만이 아니라 주요 교회 관계자인 담임목사 의 인식 역시 중요하다. 시설 개선의 주요 수혜자는 교회의 고령신도이지만 그 시설을 바꿀 수 있는 결정권은 교회 운 영을 책임지는 담임목사에게 있기 때문이다. 또한 고령신도 를 위해 바람직한 편의시설을 계획하기 위해서는 교회시설 계획에 대해 식견을 가지고 있는 건축가와 인테리어디자이

* Associate Professor, Ph.D., Department of Interior Design, Seoil University (Primary author: ompharos@seoil.ac.kr)

** Associate Professor, Ph.D., Department of Architecture, Hanbat National University (Corresponding author: dsk@hanbat.ac.kr)
너의 설치기준에 관한 전문적 의견 역시 고려할 필요가 있 다. 따라서 본 연구는 교회의 고령신도, 담임목사, 그리고 건축 및 실내디자인 전문가를 대상으로 하여 교회의 편의 시설 설치기준에 대한 인식의 차이를 조사한다. 관심사나 교육적 배경 등의 차이에 의해 필요한 편의시설의 유형이 나 중요도에 대한 인식의 차이가 있을 수 있다는 문제의식 에 의해 시작된 본 연구의 목적은 주체별로 상이한 관점에 의해 발생한 교회 편의시설 설치기준의 유형별 중요도에 대한 인식의 다양성을 종합적으로 파악하여 교회의 고령신 도를 위한 편의시설 개선 작업의 참조점을 제공하는 것이 다.

\subsection{Methods of Research}

조사는 65세 이상의 고령신도, 담임목사, 전문가 등 세 그룹을 대상으로 한다. 조사 방법은 고령신도의 경우 우편 및 방문 대면 조사를 실시하였고, 교회 관계자와 전문가는 우편 및 온라인 조사를 실시하였다. 설문조사를 위한 표본 
추출은 조사대상 교회의 규모차이를 고려하여 비례 표본추 출을 하였다. 먼저 설문지를 배포할 교회의 고령자 수를 파 악한 후, 해당 교회의 고령신도 중 30\%에 해당하는 부수의 설문지를 각각 발송하였다. 65세 이상의 신도를 대상으로 하여 50곳의 교회에 발송한 2230 부의 설문지 중 총 534 부 가 회수되었다(응답율 약 $23.9 \%$ ). 내용이 불충분 한 118 부 는 분석에서 제외하여, 회수된 설문지 중 총 410 부가 분석 되었다. 교회관계자 조사대상은 교회 건축의 결정권을 지닌 담임목사로 한정하여 83 곳의 교회에 각각 1 부씩 총 83 부 의 설문지를 발송하였다. 51 부가 회수되었으며 (응답율 약 $61.4 \%)$, 응답이 불충분한 7 부를 제외하고, 연구의 목적에 적합한 44 부를 분석하였다. 또한 전문가를 대상으로 하여 총 20 부의 설문지가 발송되었으며, 총 16 부가 회수 되었다 (응답율 $80.0 \%$ ). 설문 응답은 1(매우 그렇지 않다)에서 5 ( 매우 그렇다)의 5단계 척도로 기록하게 하였다.

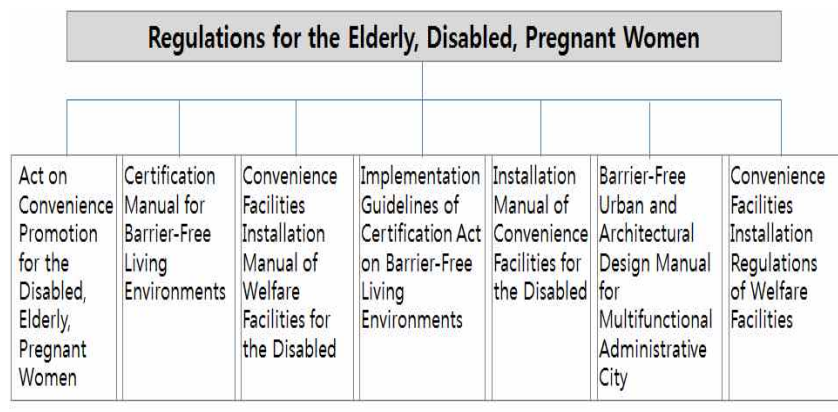

Evaluation Factors of Convenience Facilities for the Elderly

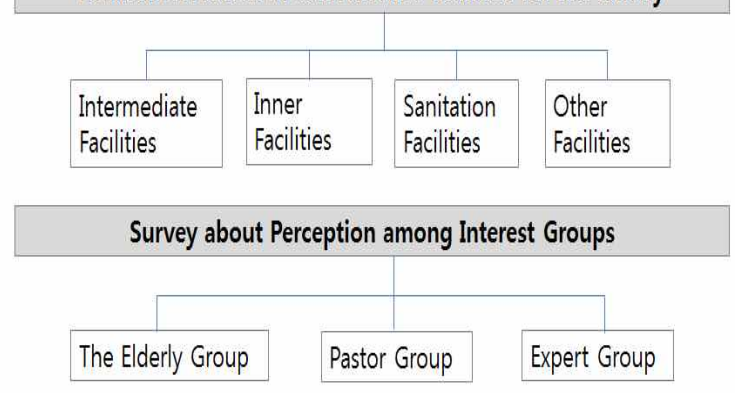

[Figure 1] Extraction of Evaluation Factors and Research Process

편의시설 설치에 대한 실제 법규가 장애인 중심으로 되 어 있는데 반해 조사 대상 교회의 성도 구성을 살펴보면 장 애를 가진 성도는 극히 드물고 고령자가 다수를 차지하고 있기 때문에 고령자를 위한 평가항목의 설정이 필요하였다. 고령자를 주요 대상으로 하는 관련법규는 자료가 제한적 이어서 장애인, 노인, 임산부등을 포함한 포괄적인 법규인 편의증진법과 그 하위개념의 5가지 매뉴얼: (1)장애물 없 는 생활환경(Barrier Free) 인증제도 매뉴얼; (2)복지시설 의 장애인 편의시설 설치 매뉴얼; (3)장애물 없는 생활환경 (Barrier Free) 인증제도 시행지침; (4)서울시 장애인 편의 시설 설치매뉴얼; (5)행정중심복합도시의 장애물 없는 도
시 건축 설계 매뉴얼, 그리고 한국장애인개발원에서 제시한 복지시설의 편의시설 설치 매뉴얼의 규정을 조사하였다. 총 166 개의 문항 중에서 고령자와 관련된 법규인 56 개 문항을 추출하여 고령자를 위한 시설별 평가항목을 만들었다. 시설 분류는 관련법규의 구성에 따라 매개시설, 내부시설, 위생 시설, 기타시설 등으로 구분하였다. 추출된 평가항목의 타 당성을 검증하기 위해 건축가와 인테리어 전문가의 자문을 받았다(Figure 1). 또한 평가항목은 각각의 특성에 따라 형 태, 소재, 그리고 기능적 요소로 분류하여, 주체별로 인식하 는 평가항목의 중요도가 그 특성에 영향을 받는지도 분석 하였다.

\section{Research Trends in Convenience Facilities for the Elderly}

\subsection{Related Researches}

고령화 시대를 대비하여 건축에서도 여러 가지 개선방 안을 모색해야 한다는 인식에 의해 증가하고 있는 노인건 축에 대한 관심은 발표 논문의 급격한 증가에서도 발견된 다. 한국의료복지건축학회지 창간호부터 2010년까지의 게 재 논문에 나타난 연구동향을 분석한 연구는 학회지에 실 린 총 308 개의 논문 중 약 $23 \%$ 가 노인복지시설에 관한 연 구이며 연구의 빈도 역시 증가하고 있음을 밝히고 있다. 아 래의 표에서 보이는 것처럼 장애인 편의시설에 관한 연구 역시 지속적 증가세를 보이고 있다(Kim, 2011: 22)(Table 1).

[Table 1] Research trends to welfare facilities

\begin{tabular}{c|l|c|c|c|c|c}
\hline \multirow{2}{*}{ Target } & \multicolumn{1}{|c|}{ Type } & 1995 & $\begin{array}{c}1996- \\
2000\end{array}$ & $\begin{array}{c}2001- \\
2005\end{array}$ & $\begin{array}{c}2006- \\
2010\end{array}$ & Sum \\
\hline \multirow{4}{*}{$\begin{array}{c}\text { the } \\
\text { elderly }\end{array}$} & Medical welfare & 0 & 15 & 10 & 15 & 40 \\
\cline { 2 - 7 } & Residential welfare & 0 & 4 & 1 & 10 & 15 \\
\cline { 2 - 7 } & In-house care & 0 & 2 & 3 & 5 & 10 \\
\cline { 2 - 7 } & Leisure welfare & 0 & 1 & 2 & 3 & 6 \\
\hline $\begin{array}{c}\text { the } \\
\text { disabled }\end{array}$ & $\begin{array}{l}\text { Convenience } \\
\text { facilities }\end{array}$ & 0 & 1 & 8 & 15 & 24 \\
\hline
\end{tabular}

장애인의 편의증진을 위한 연구의 관심은 건축물부문 장 애물 없는 생활환경 인증을 받은 건축물의 평가지표 개선 연구(Lee \& Kang, 2011: 25-37)와 매개시설 설치현황조 사연구(Lee \& Kim, 2012: 33-43), 공연시설을 대상으로 한 장애인 편의시설 개선방안 연구(Kim et.al., 2012: 4554), 그리고 장애인을 위한 공공스포츠시설 개선방안 연구 (Seong, 2012: 89-97) 등에서 지속적으로 발견된다.

고령자를 대상으로 하여 그들의 신체적 특성이나 요구 에 관련된 건축공간에 대한 연구는 주로 노인주거(You \& 
Park, 2011: 7-16; Moon, 2011: 7-14; Kim, 2012: 1928)와 노인요양시설 및 의료복지시설(Yun et.a.1, 2011: 33-40; Chai, 2011: 15-22; Yun \& Chai, 2011: 17-26; Tak et.al., 2012: 45-52) 등을 중심으로 이루어지고 있다. 이러한 연구는 대개 설문조사나 면접을 통해 고령자가 경 험하는 시설의 불편 사항, 안전 실태, 만족도 등을 조사하고 개선 방안 등을 제시하고 있다.

교회를 대상으로 한 연구는 주로 교회의 건축적 특징, 장 애인의 접근성, 그리고 사회적 기능 등과 같은 범주에서 발 견된다(Lee \& Park, 2005: 191-194; Lee et.al., 2009: 31-38; Ju \& Lee, 2006: 409-414; Lee \& Lee, 1995: 159-162; Yoon \& Song, 1994: 13-24; Lee, 2011: 137144; Kim \& Cho, 2006: 21-24; Woo \& Lee, 2002: 307310). 그러나 고령자의 구성비율이 점진적으로 증가하고 있는 교회건축을 대상으로 하여 고령신도의 편의성을 증진 시키기 위한 시설개선 연구는 거의 이루어지지 않고 있다 (Lee, 2009: 298-308).

\subsection{Evaluation Factors of Churches' Convenience Facilities for the Elderly}

1) Intermediate Facility

매개시설은 크게 접근로의 6개 항목과 주차장 3 개 항목 으로 구분할 수 있다. 평가항목은 고령자의 신체적 특징을 고려하여 만들어진 내용이므로 공통적으로 모든 항목이 기 능적 요소를 포함하고 있다. 그 중 '보도 및 접근로의 경사 로 기울기를 $1 / 12$ 이하로 계획'과 '장애인과 동일한 크기의 고령자 전용 주차구역' 설치의 경우 형태적 요소를 가진다. 한편 '보도 및 접근로의 평평하고 미끄럽지 않는 재질 사용' 과 '외부 계단이나 경사로 측면의 손잡이에 겨울에 차갑지 않는 소재 사용'은 소재적 요소의 특징을 갖고 있다(Table 2).

[Table 2] Intermediate facilities and categorization

\begin{tabular}{|c|c|c|}
\hline & Intermediate facilities & Factor \\
\hline \multirow{6}{*}{ Access road } & Pedestrian-only access road & $\bullet$ \\
\hline & $\begin{array}{l}\text { Ramp with slope under } 1 / 18 \text { (1/12 in } \\
\text { necessary) }\end{array}$ & $\circ \bullet$ \\
\hline & Flat \& nonslip floor & ()• \\
\hline & $\begin{array}{l}\text { Thawing device \& roof on freezing } \\
\text { section of stair \& slope }\end{array}$ & - \\
\hline & $\begin{array}{l}\text { Both sides safety rails of stair \& } \\
\text { slope }\end{array}$ & - \\
\hline & $\begin{array}{l}\text { Not-cold handle of rail on outside } \\
\text { stair or slope in winter }\end{array}$ & () • \\
\hline \multirow{3}{*}{$\begin{array}{l}\text { Parking lots for } \\
\text { the elderly }\end{array}$} & Sign of the elderly only & $\bullet$ \\
\hline & Same size for the disabled & $\circ \bullet$ \\
\hline & Parking lots-the elderly only & - \\
\hline
\end{tabular}

○ Form factor; () Material factor; • Function factor
2) Inner Facility

내부시설은 내외부 출입구인 주출입구 3 개 항목과 일반 출입구 3 개 항목, 복도 5 개 항목, 계단 9개 항목, 그리고 승 강기 6개 항목으로 구성되어 있다. 내부시설의 평가항목 또 한 공통적으로 기능적 요소를 포함하고 있다. 그 중 형태 적 요소를 포함하는 문항은 '모든 출입구에서의 주출입구

[Table 3] Inner facilities and categorization

\begin{tabular}{|c|c|c|}
\hline & Inner facilities & Factor \\
\hline \multirow{6}{*}{$\begin{array}{l}\text { Main entrance } \\
\quad \& \text { door }\end{array}$} & $\begin{array}{l}\text { Over } 3 \text { seconds of opening \& } \\
\text { closing }\end{array}$ & $\bullet$ \\
\hline & $\begin{array}{l}\text { Height gap between main entrance } \\
\& \text { passage under } 20 \mathrm{~mm}\end{array}$ & $\circ \bullet$ \\
\hline & $\begin{array}{l}\text { Adhesion of color strip in case of a } \\
\text { clear glass door }\end{array}$ & ( ) • \\
\hline & $\begin{array}{l}\text { Shape of handle(vertical, horizontal, } \\
\text { or lever type) of door }\end{array}$ & $\bullet$ \\
\hline & $\begin{array}{l}\text { Penetrating window, } 600 \mathrm{~mm} \text { from } \mathrm{fl} \text {, } \\
\text { width } 200 \mathrm{~mm} \text {, length } 900 \mathrm{~mm}\end{array}$ & $\circ \bullet \bullet$ \\
\hline & $\begin{array}{l}\text { Preference sliding door to hinged } \\
\text { door }\end{array}$ & $\circ \bullet$ \\
\hline \multirow{5}{*}{ Corridor } & Flat \& nonslip floor & () $\bullet$ \\
\hline & No difference of floor-Level & $\bullet$ \\
\hline & Curved corner or chamfered edge & $\circ \bullet$ \\
\hline & Safety rail on corridor wall & $\bullet$ \\
\hline & $\begin{array}{l}\text { Footlights on corners and parts of } \\
\text { changing level }\end{array}$ & $\bullet$ \\
\hline \multirow{9}{*}{ Stair } & Cut-off of rail in the middle & $\bullet$ \\
\hline & Tread width(over 280mm) & $\circ \bullet$ \\
\hline & Safety rails on both sides & $\bullet$ \\
\hline & $\begin{array}{l}\text { Resting area every height of } \\
1800 \mathrm{~mm}\end{array}$ & $\bullet$ \\
\hline & $\begin{array}{l}\text { Finishing materials at the beginning } \\
\text { and ending point of stair for warning }\end{array}$ & () $\bullet$ \\
\hline & $\begin{array}{l}\text { Reinforced identification by the clear } \\
\text { difference of brightness between } \\
\text { stair and rail color }\end{array}$ & () $\bullet$ \\
\hline & Riser height(under $180 \mathrm{~mm})$ & $\circ \bullet$ \\
\hline & $\begin{array}{l}\text { Horizontal extension of safety rail up } \\
\text { to } 300 \mathrm{~mm}\end{array}$ & $\circ \bullet$ \\
\hline & Flat and nonslip floor & () $\bullet$ \\
\hline \multirow{6}{*}{ Elevator } & $\begin{array}{l}\text { Closed location to main entrance } \\
\text { and passage }\end{array}$ & $\bullet$ \\
\hline & $\begin{array}{l}\text { Voice information about the number } \\
\text { of floors and blinking light services } \\
\text { when push the button }\end{array}$ & $\bullet$ \\
\hline & Installation of elevator & $\circ \bullet$ \\
\hline & $\begin{array}{l}\text { Glass installation on the part of } \\
\text { elevator door }\end{array}$ & ○• \\
\hline & Inner safety rail & $\bullet$ \\
\hline & $\begin{array}{l}\text { Folding chair for the elderly resting } \\
\text { in elevator }\end{array}$ & $\bullet$ \\
\hline
\end{tabular}

○ Form factor; @ Material factor; • Function factor 
와 통로의 높이 차이가 $20 \mathrm{~mm}$ 이하', '바닥에서 $600 \mathrm{~mm}$, 폭 $200 \mathrm{~mm}$, 높이 $900 \mathrm{~mm}$ 의 투시창 설치', '여닫이보다는 미닫 이문의 설치 권장', '복도의 코너부분 곡면처리나 모까기', ' 안전손잡이 $300 \mathrm{~mm}$ 연장', '계단의 디딤판 크기 $280 \mathrm{~mm}$ 이 상', 그리고 '계단의 챌판의 높이 $180 \mathrm{~mm}$ 이하'로 해야 하는 항목 등이다. 또한 소재적 요소의 특성을 지닌 항목은 '모든 출입구의 전면이 투명한 유리문일 경우 색띠 부착', '바닥 에서 $600 \mathrm{~mm}$, 폭 $200 \mathrm{~mm}$, 높이 $900 \mathrm{~mm}$ 투시창 설치', '계 단에서의 손잡이의 색상과 명도차이를 명확하게 하여 주변 과 쉽게 구분 가능', '바닥이 평평하고 미끄럽지 않는 재질 사용', '계단의 시작과 끝 지점에 경고용 바닥 마감재 사용' , 그리고 '승강기에서 출입문 일부에 유리를 장착'하는 내용 등이다(Table 3).

\section{3) Sanitation Facility}

화장실에 관한 7 개의 설치기준으로 구성되어 있는 위생 시설의 평가항목 역시 기능성을 기본으로 하고 있다. 형태 적 요소를 공유하는 조항은 "내부의 활동공간이 $1400 \mathrm{~mm} \mathrm{x}$ $1400 \mathrm{~mm}$ 이상' 되어야 하는 항목이며, 소재적 특성을 갖는 설치기준은 '바닥이 평평하고 미끄럽지 않는 재질을 사용' 하는 항목이다(Table 4).

[Table 4] Sanitation facilities and categorization

\begin{tabular}{l|l|c}
\hline & \multicolumn{1}{|c|}{ Sanitation facilities } & Factor \\
\hline \multirow{4}{*}{ Toilet } & Flat \& nonslip floor & $\bullet$ \\
\cline { 2 - 3 } & $\begin{array}{l}\text { Inner space } \\
(1400 \times 1400 \mathrm{~mm})\end{array}$ & $\bullet$ \\
\cline { 2 - 3 } & $\begin{array}{l}\text { Rack for putting one's } \\
\text { belongings on }\end{array}$ & $\bullet$ \\
\cline { 2 - 3 } & Safety rail of closet bowl & $\bullet$ \\
\cline { 2 - 3 } & Safety rail of urinal & $\bullet$ \\
\cline { 2 - 3 } & Safety rail of basin & $\bullet$ \\
\cline { 2 - 3 } & Toilet for the elderly & $\bullet$ \\
\hline
\end{tabular}

o Form factor; () Material factor; • Function factor

4) Other Facilities

기타시설의 모든 평가항목 또한 기능성 요소를 기본으 로 하고 있으며, 그 중 예배당의 4 개 항목 중 '시력이 낮은 고령자를 위한 스크린의 글씨 크기', 소그룹실의 12 개 항목 중 '바닥재질 이어지는 부분 재료분리대의 단차 제거', '큰 사이즈의 스위치' 그리고 '콘센트 높이 $900 \mathrm{~mm}-1200 \mathrm{~mm}$ ' 등은 형태적 요소를 포함하고 있는 항목이다. 소그룹실의 '광택 없고 미끄럽지 않은 바닥 재질', '쉽게 청소되는 바닥 재질', '충격 흡수성이 좋은 바닥 재질', 그리고 '어두운 곳 의 벽과 바닥 색 구별이 분명한 마감재' 등은 소재적 요소를 포함하고 있다.
[Table 5] Other facilities and categorization

\begin{tabular}{|c|c|c|}
\hline & Other facilities & Factor \\
\hline \multirow{4}{*}{ Chapel } & $\begin{array}{l}\text { Screen size for the elderly with } \\
\text { defective vision }\end{array}$ & $\circ \bullet$ \\
\hline & Hearing aid equipment & $\bullet$ \\
\hline & $\begin{array}{l}\text { Floor heating for the elderly with } \\
\text { knee-joints problem }\end{array}$ & $\bullet$ \\
\hline & Seats for the elderly & $\bullet$ \\
\hline \multirow{12}{*}{$\begin{array}{l}\text { Small group } \\
\text { meeting room }\end{array}$} & Gloss-less \& nonslip floor & () $\bullet$ \\
\hline & Floor materials for easy cleaning & () $\bullet$ \\
\hline & Ambient and bright lighting fixtures & $\bullet$ \\
\hline & $\begin{array}{l}\text { Removal of gap of dividing strip to } \\
\text { joint of floor finishing materials }\end{array}$ & $\circ \bullet$ \\
\hline & $\begin{array}{l}\text { Chair at the place where taking off } \\
\text { shoes }\end{array}$ & $\bullet$ \\
\hline & Big-size light switch & $\circ \bullet$ \\
\hline & Floor materials for absorbing shocks & () $\bullet$ \\
\hline & Storage space & $\bullet$ \\
\hline & $\begin{array}{l}\text { Wall plug location of } 900-1200 \mathrm{~mm} \\
\text { over the floor }\end{array}$ & $\circ \bullet$ \\
\hline & $\begin{array}{l}\text { Change of the intensity of illumination } \\
\text { between adjacent rooms }\end{array}$ & $\bullet$ \\
\hline & $\begin{array}{l}\text { Lighting fixtures for clearly } \\
\text { differentiating colors }\end{array}$ & $\bullet$ \\
\hline & $\begin{array}{l}\text { Finishing materials to discern colors } \\
\text { of dark wall and floor }\end{array}$ & () $\bullet$ \\
\hline
\end{tabular}

○ Form factor; @ Material factor; • Function factor

\section{Results}

\subsection{General Characteristics of Survey Constituents}

설문응답자의 성별 특성을 살펴보면, 고령자의 경우는 여성 $(81.5 \%)$ 이 다수인 반면 교회 관계자인 담임 목사와 건 축/인테리어 전문가는 남성의 수가 많았다(각각 $100.0 \%$, $68.8 \%)$. 연령특성으로 고령신도 그룹은 65세 이상-74 세 이하(88.0\%), 담임목사 그룹은 50세 이상-59세 이 하(52.5\%), 그리고 전문가 그룹은 40세 이상-49세 이하 (56.2\%)가 응답률이 가장 높았다. 지역적 특성으로는 고령 자(78.7\%)와 담임목사 $57.1 \%)$ 의 교회는 강북이 많았고, 건축 전문가 $(75 \%)$ 의 사무실은 강남이 많았다.

고령자의 교회 출석 연수는 30년 이상 $34.1 \%)$ 이 가장 많았고, 교회 관계자인 담임 목사의 시무 연수는 9년 이하 (45.2\%), 건축 전문가는 10 년 이상-19년 이하(37.5\%)가 다수였다. 고령자가 다니는 교회와 설문조사에 응답한 담임 목사가 소속된 교회의 설립역사는 30년 이상(각각 $93.1 \%$ 와 $44.1 \%)$ 이 가장 많았고, 건축 및 인테리어 전문가의 회 사 설립역사는 모두 20 년 이하 $(100.0 \%)$ 였다. 교회의 신축 또는 리모델링 시기는 고령자가 출석하는 교회와 담임목사 
[Table 6] General characteristics of informants

\begin{tabular}{|c|c|c|c|c|c|c|c|}
\hline \multirow[t]{2}{*}{ Category } & & \multicolumn{2}{|c|}{$\begin{array}{l}\text { Aged } \\
\text { Believer }\end{array}$} & \multicolumn{2}{|c|}{ Pastor } & \multicolumn{2}{|c|}{ Expert } \\
\hline & & $\#$ & $(\%)$ & $\#$ & (\%) & $\#$ & $(\%)$ \\
\hline \multirow{3}{*}{ Gender } & Male & 76 & (18.5) & 44 & (100) & 11 & $(68.8)$ \\
\hline & Female & 334 & $(81.5)$ & 0 & (0) & 5 & (31.3) \\
\hline & Sum & 410 & $(100)$ & 44 & $(100)$ & 16 & (100) \\
\hline \multirow{7}{*}{ Age } & $40-49$ & 0 & (0) & 8 & $(20)$ & 9 & $(56.2)$ \\
\hline & 50-59 & 0 & (0) & 21 & (52.5) & 7 & $(43.8)$ \\
\hline & $60-64$ & 0 & (0) & 11 & $(27.5)$ & 0 & (0) \\
\hline & $65-69$ & 263 & (65.9) & 0 & (0) & 0 & (0) \\
\hline & 70-74 & 88 & (22.1) & 0 & (0) & 0 & (0) \\
\hline & $75-79$ & 48 & (12) & 0 & (0) & 0 & (0) \\
\hline & Sum & 399 & (100) & 40 & (100) & 16 & $(100)$ \\
\hline \multirow{3}{*}{ Location } & $\begin{array}{c}\text { Kang- } \\
\text { nam }\end{array}$ & 83 & (20) & 18 & (42.9) & 12 & (75) \\
\hline & Kangbuk & 327 & (78.7) & 24 & (57.1) & 4 & (25) \\
\hline & Sum & 410 & (100) & 42 & (100) & 16 & (100) \\
\hline \multirow{6}{*}{$\begin{array}{c}\text { Attendance } \\
\text { year }\end{array}$} & Under 5 & 22 & $(5.4)$ & 1 & (2.3) & 3 & $(18.8)$ \\
\hline & $5-9$ & 51 & (12.5) & 18 & (42.9) & 5 & (31.3) \\
\hline & $10-19$ & 85 & (20.8) & 12 & (28.6) & 6 & (37.5) \\
\hline & $20-29$ & 111 & $(27.2)$ & 11 & $(26.2)$ & 2 & (12.5) \\
\hline & Over 30 & 139 & (34.1) & 0 & (0) & 0 & (0) \\
\hline & Sum & 408 & $(100)$ & 42 & (100) & 16 & (100) \\
\hline \multirow{4}{*}{$\begin{array}{c}\text { Establishment } \\
\text { History }\end{array}$} & $\begin{array}{l}\text { Under } \\
20\end{array}$ & 10 & $(2.5)$ & 8 & (18.6) & 16 & (100) \\
\hline & $20-29$ & 18 & $(4.4)$ & 16 & $(37.2)$ & 0 & (0) \\
\hline & Over 30 & 379 & (93.1) & 19 & $(44.1)$ & 0 & (0) \\
\hline & Sum & 407 & $(100)$ & 43 & $(100)$ & 16 & $(100)$ \\
\hline \multirow{5}{*}{$\begin{array}{c}\text { Construction } \\
\text { or remodeling }\end{array}$} & Under 10 & 220 & $(55.4)$ & 27 & $(65.9)$ & \multirow{7}{*}{-} & \multirow{7}{*}{-} \\
\hline & 10-19 & 51 & (12.8) & 13 & $(31.7)$ & & \\
\hline & $20-29$ & 31 & $(7.8)$ & 1 & $(2.4)$ & & \\
\hline & Over 30 & 95 & (23.9) & 0 & (0) & & \\
\hline & Sum & 397 & (100) & 41 & (100) & & \\
\hline \multirow{4}{*}{ Believers \# } & 500-999 & 156 & $(38.8)$ & 11 & $(25.6)$ & & \\
\hline & $\begin{array}{c}1000- \\
1999\end{array}$ & 161 & (40) & 24 & $(55.8)$ & & \\
\hline & $\begin{array}{c}2000- \\
2999\end{array}$ & 85 & $(21.1)$ & 8 & (18.6) & \multirow{8}{*}{-} & \multirow{8}{*}{ - } \\
\hline & Sum & 402 & (100) & 43 & (100) & & \\
\hline \multirow{6}{*}{ Elderly \% } & $\begin{array}{l}10 \% \\
\text { Under }\end{array}$ & 21 & (5.2) & 0 & (0) & & \\
\hline & $10 \%-19 \%$ & 130 & (32.4) & 6 & (14) & & \\
\hline & $\begin{array}{l}20 \%- \\
29 \%\end{array}$ & 129 & (32.2) & 8 & (18.6) & & \\
\hline & $\begin{array}{l}30 \%- \\
39 \%\end{array}$ & 73 & (18.2) & 13 & (30.3) & & \\
\hline & $\begin{array}{l}\text { Over } \\
40 \%\end{array}$ & 48 & (12) & 16 & $(37.2)$ & & \\
\hline & Sum & 401 & (100) & 43 & (100) & & \\
\hline
\end{tabular}

가 시무하는 교회 모두 10 년 미만이 많았다(각각 $55.4 \%$ 와 65.9\%).

교인 전체 성도수로는 고령자가 출석하는 교회와 담임목 사가 시무하는 교회 모두 1000-2000명 미만(각각 40.0\% 와 55.8\%)이 가장 많았다. 고령신도는 전체성도 수 비례 약 10-19\%(32.4\%)에 가장 많이 분포되어 있었고, 담임목사 가 시무하는 교회는 고령자의 비율이 $40 \%$ 이상 $(37.2 \%)$ 인 교회가 가장 많았다(Table 6).

\subsection{Perception to Convenience Facilities among Interest Groups}

1) Intermediate Facility

매개시설의 접근로에 대한 고려사항 중에 고령자를 위해 가장 중요하다고 인식하는 부분은 '차로와 분리된 보행안 전 통로(전체 4.12)'였으며, 설문 응답자 그룹 사이에서 발 견되는 중요도 인식의 차이는 전문가 그룹(4.88), 담임목사 그룹(3.77), 그리고 고령신도(3.70)의 순으로 나타났다. 그 룹별로 각 항목에 대한 중요도 인식의 차이가 발견된다. 고 령신도 그룹은 '차도와 분리된 보행안전 통로(3.70)'를 가 장 중요하게 인식하는 하고 있으며 다음으로는 '경사로 결 빙구간에 지붕설치(3.51)', 그리고 '외부계단이나 경사로 측면 손잡이에 겨울에 차갑지 않은 소재의 사용(3.43)' 등 의 순으로 그 중요도를 인식하고 있다. 담임목사 그룹은 '차 도와 분리된 보행안전 통로(3.77)' 외에, '평평하고 미끄럽 지 않은 재질 사용(3.75)', 그리고 '경사로 결빙구간에 지 붕설치(3.73)' 등을 중요요소로 인식하고 있다. 반면에 전 문가 그룹은 '차도와 분리된 보행안전 통로(4.88)', '경사 로 기울기(4.50)'와 ‘평평하고 미끄럽지 않은 재질 사용 (4.50)', 그리고 '경사로 양쪽 안전손잡이 (4.19)' 등의 순 서로 중요성을 인식하고 있다. 상대적으로 그 중요도가 높 지 않다고 인식하는 부분에서 각 그룹별로 차이가 발견된 다. 고령신도 그룹은 '평평하고 미끄럽지 않은 재질 사용 (3.18)'을 상대적으로 가장 중요하지 않다고 인식하고 있으 나, 담임목사 그룹은 '경사로 양쪽 안전손잡이(3.52)’를, 그 리고 전문가 그룹은 '외부계단이나 경사로 측면 손잡이에 겨울에 차갑지 않은 소재 사용(3.88)'을 상대적으로 가장 중요하지 않다고 인식하고 있다.

고령자 전용 주차구역에 대한 주체별 인식의 차이를 보 면, 고령신도 그룹과 담임목사 그룹은 '고령자 전용주차구 역 표시(각각 3.55와 3.86)'를 가장 중요한 요소로 인식하 고 있으나, 전문가 그룹은 '장애인과 동일한 크기의 고령자 전용 주차주역 (4.00)'을 가장 중요한 요소로 인식하고 있다 (Table 7).

2) Inner Facility

내부시설의 출입구를 구성하는 요소들의 중요도에 대한 
인식은 주체별로 상이한 경향을 보이고 있다. 고령신도 그 룹은 '주출입구와 통로의 높이 차이가 $20 \mathrm{~mm}$ 이하(3.65)' 를 가장 중요하다고 인식하고 있으나, 담임목사 그룹과 전 문가 그룹은 '주출입구의 여닫는 속도 3초 이상(각각 3.89 와 4.50)'을 고령자를 고려한 주출입구 설치와 관련된 가 장 중요한 요소로 인식하고 있다. 일반 출입구의 경우, 고 령신도 그룹과 담임목사 그룹은 '출입구의 손잡이 형태(각 각 3.57 과 3.50 )'를 가장 중요한 요소로 인식하고 있는 반 면, 전문가 그룹은 '바닥에서 $600 \mathrm{~mm}$, 폭 $200 \mathrm{~mm}$, 높이 $900 \mathrm{~mm}$ 의 투시창 설치(4.44)'와 '미닫이 문 설치(4.44)'를 가장 중요한 요소로 인식하고 있다.

[Table 7] Perception to intermediate facilities

\begin{tabular}{c|l|c|c|c|c}
\hline Item & \multicolumn{1}{|c|}{ Contents } & AB & PA & EX & Sum \\
\hline \multirow{4}{*}{} & Pedestrian-only access road & 3.70 & 3.77 & 4.88 & 4.12 \\
\cline { 2 - 6 } & $\begin{array}{l}\text { Ramp with slope under 1/18 } \\
(1 / 12 \text { in necessary) }\end{array}$ & 3.30 & 3.66 & 4.50 & 3.82 \\
\cline { 2 - 6 } & Flat \& nonslip floor & 3.18 & 3.75 & 4.50 & 3.81 \\
\cline { 2 - 6 } $\begin{array}{c}\text { Access } \\
\text { road }\end{array}$ & $\begin{array}{l}\text { Thawing device \& roof on } \\
\text { freezing section of stair \& slope }\end{array}$ & 3.51 & 3.73 & 3.94 & 3.73 \\
\cline { 2 - 6 } & $\begin{array}{l}\text { Both sides safety rails of stair \& } \\
\text { slope }\end{array}$ & 3.20 & 3.52 & 4.19 & 3.64 \\
\cline { 2 - 6 } & $\begin{array}{l}\text { Not-cold handle of rail on } \\
\text { outside stair or slope in winter }\end{array}$ & 3.43 & 3.55 & 3.88 & 3.62 \\
\cline { 2 - 6 } & Sum & 3.39 & 3.66 & 4.32 & 3.79 \\
\hline \multirow{2}{*}{$\begin{array}{c}\text { Parking } \\
\text { lots } \\
\text { for the } \\
\text { elderly }\end{array}$} & Sign of the elderly only & 3.55 & 3.86 & 3.77 & 3.73 \\
\cline { 2 - 7 } & Same size for the disabled & 3.33 & 3.55 & 4.00 & 3.63 \\
\cline { 2 - 7 } & Parking lots-the elderly only & 3.30 & 3.18 & 3.87 & 3.45 \\
\hline \multirow{2}{*}{ Sum } & 3.39 & 3.53 & 3.88 & 3.60 \\
\hline
\end{tabular}

(Hereafter, 'Aged Believer': AB; 'Paster': PA; 'Expert': EX)

내부시설의 복도에 대해서도 주체별로 상이한 인식이 발 견된다. 고령신도 그룹은 '코너부분의 곡면처리나 모까기 (3.38)', '바닥이 평평하고 미끄러지지 않는 재질(3.21)', 그리고 '턱이나 바닥면의 단차 제거(3.19)' 등의 순으로 그 중요도를 인식하고 있다. 담임목사 그룹은 '벽면의 안전손 잡이(3.84)'와 '코너 및 단차 부분에 풋라이트 설치 (3.84)' , 그리고 '턱이나 바닥면의 단차제거(3.74)' 순으로 중요도 를 인식하고 있다. 전문가 그룹은 '바닥이 평평하고 미끄러 지지 않는 재질(4.50)', '턱이나 바닥면의 단차제거(4.38)', 그리고 '코너부분 곡면처리나 모까기(4.36)'의 순으로 중요 도를 평가하고 이다.

계단에 대해 고령신도 그룹은 '높이 $1800 \mathrm{~mm}$ 마다 휴식 참 설치(3.23)', '손잡이의 색상과 명도 차이(3.16)', 그리 고 '안전을 위한 양쪽 손잡이(3.14)' 등의 순으로 중요도 를 인식하고 있다. 담임목사 그룹의 계단 구성요소의 중요 도에 대한 인식의 차이는 '안전을 위한 양쪽 손잡이(3.86)'
[Table 8] Perception to inner facilities

\begin{tabular}{|c|c|c|c|c|c|}
\hline Item & Contents & $A B$ & PA & EX & Sum \\
\hline \multirow{8}{*}{ 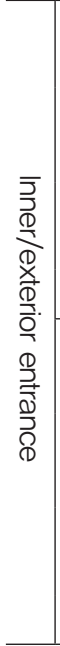 } & $\begin{array}{l}\text { Over } 3 \text { seconds of opening \& } \\
\text { closing }\end{array}$ & 3.17 & 3.89 & 4.50 & 3.85 \\
\hline & $\begin{array}{l}\text { Height gap between main en- } \\
\text { trance \& passage under } 20 \mathrm{~mm}\end{array}$ & 3.65 & 3.64 & 4.14 & 3.81 \\
\hline & $\begin{array}{l}\text { Adhesion of color strip in case of } \\
\text { a clear glass door }\end{array}$ & 3.42 & 2.73 & 4.38 & 3.51 \\
\hline & Sum & 3.41 & 3.42 & 4.34 & 3.72 \\
\hline & $\begin{array}{l}\text { Shape of handle(vertical, horizon- } \\
\text { tal, or lever type) of door }\end{array}$ & 3.57 & 3.50 & 4.33 & 3.80 \\
\hline & $\begin{array}{l}\text { Penetrating window, } 600 \mathrm{~mm} \text { from } \\
\mathrm{fl} \text {, width } 200 \mathrm{~mm} \text {, length } 900 \mathrm{~mm}\end{array}$ & 3.53 & 3.42 & 4.44 & 3.80 \\
\hline & $\begin{array}{l}\text { Preference sliding door to hinged } \\
\text { door }\end{array}$ & 2.93 & 2.91 & 4.44 & 3.43 \\
\hline & Sum & 3.34 & 3.28 & 4.40 & 3.68 \\
\hline \multirow{6}{*}{$\begin{array}{l}\text { 을. } \\
\text { 을 }\end{array}$} & Flat \& nonslip floor & 3.21 & 3.61 & 4.50 & 3.77 \\
\hline & No difference of floor-Level & 3.19 & 3.74 & 4.38 & 3.77 \\
\hline & Curved corner or chamfered edge & 3.38 & 3.40 & 4.36 & 3.71 \\
\hline & Safety rail on corridor wall & 3.07 & 3.84 & 3.63 & 3.51 \\
\hline & $\begin{array}{l}\text { Footlights on corners and parts of } \\
\text { changing level }\end{array}$ & 2.69 & 3.84 & 3.67 & 3.40 \\
\hline & 소계 & 3.11 & 3.69 & 4.11 & 3.63 \\
\hline \multirow{10}{*}{ 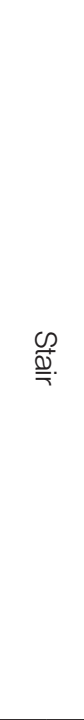 } & Cut-off of rail in the middle & 3.11 & 3.59 & 4.75 & 3.82 \\
\hline & Tread width(over 280mm) & 3.13 & 3.73 & 4.44 & 3.77 \\
\hline & Safety rails on both sides & 3.14 & 3.86 & 4.25 & 3.75 \\
\hline & $\begin{array}{l}\text { Resting area every height of } \\
1800 \mathrm{~mm}\end{array}$ & 3.23 & 3.82 & 4.13 & 3.73 \\
\hline & $\begin{array}{l}\text { Finishing materials at the begin- } \\
\text { ning and ending point of stair for } \\
\text { warning }\end{array}$ & 3.12 & 3.64 & 4.13 & 3.63 \\
\hline & $\begin{array}{l}\text { Reinforced identification by the } \\
\text { clear difference of brightness } \\
\text { between stair and rail color }\end{array}$ & 3.16 & 3.50 & 4.13 & 3.60 \\
\hline & Riser height(under $180 \mathrm{~mm}$ ) & 3.09 & 3.68 & 4.00 & 3.59 \\
\hline & $\begin{array}{l}\text { Horizontal extension of safety rail } \\
\text { up to } 300 \mathrm{~mm}\end{array}$ & 3.12 & 3.73 & 3.63 & 3.49 \\
\hline & Flat and nonslip floor & 3.11 & 3.74 & 3.50 & 3.45 \\
\hline & Sum & 3.13 & 3.70 & 4.11 & 3.65 \\
\hline \multirow{7}{*}{ 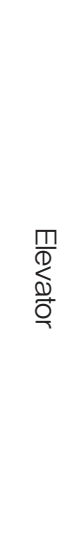 } & $\begin{array}{l}\text { Closed location to main entrance } \\
\text { and passage }\end{array}$ & 3.45 & 3.47 & 4.60 & 3.84 \\
\hline & $\begin{array}{l}\text { Voice information about the } \\
\text { number of floors and blinking light } \\
\text { services when push the button }\end{array}$ & 3.42 & 3.60 & 4.25 & 3.76 \\
\hline & Installation of elevator & 3.73 & 3.21 & 4.31 & 3.75 \\
\hline & $\begin{array}{l}\text { Glass installation on the part of } \\
\text { elevator door }\end{array}$ & 3.41 & 3.50 & 4.33 & 3.75 \\
\hline & Inner safety rail & 3.56 & 3.47 & 4.13 & 3.72 \\
\hline & $\begin{array}{l}\text { Folding chair for the elderly resting } \\
\text { in elevator }\end{array}$ & 2.33 & 3.45 & 3.67 & 3.15 \\
\hline & Sum & 3.32 & 3.45 & 4.22 & 3.66 \\
\hline \multicolumn{2}{|r|}{ Total } & 3.23 & 3.56 & 4.19 & 3.66 \\
\hline
\end{tabular}


, '높이 1800mm마다 휴식참 설치(3.82)', 그리고 '평평하 고 미끄럽지 않은 바닥재질(3.74)' 등의 순서로 나타났다. 전문가 그룹은 '손잡이의 중간 끊김(4.75)', '디딤판 크기 (280mm이상) (4.44)', 그리고 '안전을 위한 양쪽 손잡이 (4.25)' 등이 고령자의 계단 이용을 위한 중요 요소라고 인 식하고 있다.

승강기와 관련된 편의성에 대해, 고령신도는 '승강기 설 치(3.73)', '내부의 안전 손잡이(3.56)', 그리고 '주 출입구 나 통로에서 인지하기 쉽고 가까운 곳 위치(3.45)' 등을 중 요요소로 인식하고 있다. 담임목사 그룹은 '내부버튼을 누 르면 점멸등 켜짐 및 층수에 관한 음성안내(3.60)', '출입 문 일부에 유리 장착(3.50)', 그리고 '내부의 안전 손잡이 (3.47)'와 '주 출입구나 통로에서 인지하기 쉽고 가까운 곳 위치 (3.47)'를 중요한 고려사항으로 인지하고 있다. 반면에 전문가 그룹은 '주 출입구나 통로에서 인지하기 쉽고 가까 운 곳 위치(4.60)'를 가장 중요한 요소로 인식하고 있으며, '출입문 일부에 유리 장착(4.33)' 등을 중요 요소로 인식하 고 있다(Table 8).

\section{3) Sanitation Facility}

위생시설의 경우, 화장실의 '바닥이 평평하고 미끄럽지 않은 재질'로 설치해야 한다는 내용과 화장실의 '내부 활동 공간 확보'에 대한 중요성은 전체 그룹들의 의견을 종합했 을 때 가장 중요한 요소로 인식되고 있다(전체평균 3.89). 그러나 주체별로는 위생시설의 화장실 요소의 중요도에 대 한 상이한 인식을 보이고 있다. 바닥이 '평평하고 미끄럽지 않은 재질'로 마감되어야 한다는 인식은 위생시설의 화장 실과 관련된 여러 항목 중 전문가 그룹(4.69)에서 가장 높 게 나타났으며, 다음으로 담임목사 그룹(3.79)과 고령성도 (3.19)의 순으로 그 중요도를 높게 인식하고 있다. 그러나 고령신도 그룹은 '대변기 주변의 안전 손잡이 설치(3.56)' , '내부 선반 설치(3.51)', 그리고 '소변기 주변의 안전 손 잡이 (3.48)'를 가장 중요한 요소로 인식하고 있으며, '바 닥이 평평하고 미끄럽지 않은 재질(3.19)'로 설치해야 한 다는 내용은 가장 중요도가 낮은 항목으로 인식하고 있다. 반면에 담임목사 그룹은 '화장실의 내부 활동 공간(3.86)' , '바닥이 평평하고 미끄럽지 않은 재질(3.79)', 그리고 '세 면대 주변의 안전 손잡이 (3.69)'의 순으로 중요도를 인식하 고 있으며, '고령자 전용 화장실'에 대해서는 가장 중요도가 낮은 고령신도를 위한 고려사항으로 인식하고 있다(3.39) (Table 9).

\section{4) Other Facilities}

교회에 대한 편의증진법의 분류기준으로는 기타시설 중 의 하나인 예배당에서 '시력이 낮은 고령자를 위한 스크린 의 글씨 크기'는 가장 중요한 요소로 인식되고 있다(전체평
[Table 9] Perception to sanitation facilities

\begin{tabular}{c|l|c|c|c|c}
\hline Item & \multicolumn{1}{|c|}{ Contents } & AB & PA & EX & Sum \\
\hline \multirow{5}{*}{ Toilet } & Flat \& nonslip floor & 3.19 & 3.79 & 4.69 & 3.89 \\
\cline { 2 - 6 } & $\begin{array}{l}\text { Inner space } \\
(1400 X 1400 \mathrm{~mm})\end{array}$ & 3.42 & 3.86 & 4.38 & 3.89 \\
\cline { 2 - 6 } & $\begin{array}{l}\text { Rack for putting one's } \\
\text { belongings on }\end{array}$ & 3.51 & 3.64 & 4.38 & 3.84 \\
\cline { 2 - 6 } & Safety rail of closet bowl & 3.56 & 3.55 & 4.13 & 3.75 \\
\cline { 2 - 6 } & Safety rail of urinal & 3.48 & 3.55 & 4.07 & 3.70 \\
\cline { 2 - 6 } & Safety rail of basin & 3.32 & 3.69 & 4.07 & 3.69 \\
\cline { 2 - 6 } & Toilet for the elderly & 3.22 & 3.39 & 3.40 & 3.34 \\
\hline \multicolumn{2}{|c}{ 전체 } & 3.39 & 3.64 & 4.16 & 3.73 \\
\hline
\end{tabular}

[Table 10] Perception to other facilities

\begin{tabular}{|c|c|c|c|c|c|}
\hline Item & Contents & $A B$ & PA & EX & Sum \\
\hline \multirow{5}{*}{ Chapel } & $\begin{array}{l}\text { Screen size for the elderly } \\
\text { with defective vision }\end{array}$ & 3.65 & 3.65 & 4.13 & 3.81 \\
\hline & Hearing aid equipment & 3.28 & 3.23 & 3.57 & 3.36 \\
\hline & $\begin{array}{l}\text { Floor heating for the } \\
\text { elderly with knee-joints } \\
\text { problem }\end{array}$ & 3.12 & 3.09 & 3.57 & 3.26 \\
\hline & Seats for the elderly & 2.79 & 2.86 & 3.25 & 2.97 \\
\hline & Sum & 3.21 & 3.21 & 3.63 & 3.35 \\
\hline \multirow{13}{*}{$\begin{array}{l}\text { Small } \\
\text { group } \\
\text { meeting } \\
\text { room }\end{array}$} & Gloss-less \& nonslip floor & 3.68 & 3.68 & 4.50 & 3.95 \\
\hline & $\begin{array}{l}\text { Floor materials for easy } \\
\text { cleaning }\end{array}$ & 3.71 & 3.95 & 4.13 & 3.93 \\
\hline & $\begin{array}{l}\text { Ambient and bright } \\
\text { lighting fixtures }\end{array}$ & 3.65 & 3.56 & 4.53 & 3.91 \\
\hline & $\begin{array}{l}\text { Removal of gap of } \\
\text { dividing strip to joint of } \\
\text { floor finishing materials }\end{array}$ & 3.63 & 3.56 & 4.36 & 3.85 \\
\hline & $\begin{array}{l}\text { Chair at the place where } \\
\text { taking off shoes }\end{array}$ & 3.43 & 3.74 & 4.20 & 3.79 \\
\hline & Big-size light switch & 3.68 & 3.31 & 4.25 & 3.75 \\
\hline & $\begin{array}{l}\text { Floor materials for } \\
\text { absorbing shocks }\end{array}$ & 3.50 & 3.52 & 4.00 & 3.67 \\
\hline & Storage space & 3.66 & 3.33 & 3.89 & 3.63 \\
\hline & $\begin{array}{l}\text { Wall plug location of } \\
900-1200 \mathrm{~mm} \text { over the } \\
\text { floor }\end{array}$ & 3.15 & 3.70 & 3.67 & 3.51 \\
\hline & $\begin{array}{l}\text { Change of the intensity } \\
\text { of illumination between } \\
\text { adjacent rooms }\end{array}$ & 3.58 & 3.36 & 3.50 & 3.48 \\
\hline & $\begin{array}{l}\text { Lighting fixtures for clearly } \\
\text { differentiating colors }\end{array}$ & 3.58 & 2.67 & 4.19 & 3.48 \\
\hline & $\begin{array}{l}\text { Finishing materials to } \\
\text { discern colors of dark } \\
\text { wall and floor }\end{array}$ & 3.41 & 3.39 & 3.56 & 3.45 \\
\hline & Sum & 3.56 & 3.48 & 4.07 & 3.70 \\
\hline & Total & 3.47 & 3.41 & 3.96 & 3.61 \\
\hline
\end{tabular}


균 3.81). 각각의 그룹들도 모두 고령신도에게 필요한 예배 당의 중요한 고려사항으로 인식하고 있다(고령신도 그룹 3.65; 담임목사 그룹 3.65; 전문가 그룹 4.13). 또한 공통 적으로 '고령자 전용좌석'에 대해서는 가장 중요도가 낮은 요소로 인식하고 있다(고령신도 그룹 2.79; 담임목사 그룹 2.86; 전문가 그룹 3.25).

소 그룹실에 대해서는 평균적으로 '광택이 없고 미끄럽 지 않은 바닥 재질(3.95)'이 가장 중요한 고령신도를 고려 한 요소로 인식되고 있다. 주체별로 세분화해서 보면, 고령 신도 그룹의 경우 '쉽게 청소되는 바닥 재질(3.71)', '광택없 고 미끄럽지 않은 바닥재질(3.68)', 그리고 '큰 사이즈의 스 위치 (3.68)' 순으로 그 중요성을 인식하고 있다. '콘센트의 높이 900-1200mm(3.15)'에 대해서는 가장 중요도를 낮게 인식하고 있다. 담임목사 그룹의 경우에는, '쉽게 청소되는 바닥 재질(3.95)', '신발 벗는 곳의 간이의자(3.74)', 그리고 '콘센트의 높이 900-1200mm(3.70)'를 중요요소로 인식 하고 있으나, '큰 사이즈의 스위치 (3.31)'는 그 중요도를 가 장 낮게 인식하고 있다. 반면에 전문가 그룹은 '은은하고 밝 은 빛을 내는 조명기구(4.53)', '광택없고 미끄럽지 않은 바 닥 재질 (4.50)', 그리고 바닥 재질이 이어지는 부분의 재료 분리대 단차 제거 (4.36) '순으로 그 중요도를 인식하고 있 다. '인접실의 조도변화(3.50)'는 가장 중요도가 낮은 고령 신도를 위한 고려사항으로 인식하고 있다(Table 10).

\section{Perception to Significance of Churches' Convenience Facilities for the Elderly}

\subsection{Perception to Significance of Churches' Convenience Facilities due to Facility Types}

전문가 그룹은 다른 그룹에 비해 거의 모든 항목에서 고 령신도를 위해 교회의 편의시설이 확충되어야 한다는 인식 을 보이고 있다. 이는 노인의 특성과 요구에 대한 전문가로 서의 이상적 제안으로 보인다. 시설별로 설치기준에 대한 이해그룹간의 인식을 보면, 매개시설의 접근로에 대한 중요 도 인식은 전문가(4.32)>담임목사(3.66)〉고령신도(3.39) 순으로 나타난다. 고령자 전용주차구역에 대한 인식 역시 전문가(3.88)>담임목사(3.53)〉고령신도(3.39)의 순이다. 내부시설의 중요요소에 대한 인식에서는 담임목사와 고령 신도 사이에서 차이가 발견된다. 내외부 출입구의 설치기준 에 대한 중요도 인식은 전문가(4.40)>고령신도(3.34)>담임 목사(3.28)의 순으로 나타난다. 복도, 계단, 승강기에 대해 서는 각각 전문가(4.11, 4.11, 4.22) 담임목사(3.69, 3.70, $3.45)>$ 고령신도 $(3.11,3.13,3.32)$ 의 순으로 그 중요도를 인식하고 있다. 위생시설의 중요요소에 대한 인식은 전문가 (4.16)>담임목사(3.64)〉고령신도(3.39)의 순으로 나타난
다. 기타시설의 예배당에 대해서는 전문가(3.63)>담임목사 (3.21) =고령신도 (3.21)의 순으로 그 중요도를 인식하고 있 다. 반면에 소 그룹실 설치기준의 중요성에 대해서는 전문 가(3.96)〉고령신도(3.47)〉담임목사(3.41)의 순으로 인식 하고 있다.

구체적으로 보면, 고령신도의 경우 내외부 출입구의 설치 기준에 대해 담임목사 그룹보다 중요하게 인식하고 있다. 또 한 예배당 외에도 친교 등의 목적으로 빈번히 사용하게 되 는 기타시설의 소 그룹실에 대해 높은 관심을 보이고 있다.

\subsection{Perception to Significance of Churches' Convenience Facilities among Interest Groups}

1) Significant Convenience Facilities

가장 중요하다고 인식하는 설치기준에 대해 주체별로 상 이한 인식의 차이를 보이고 있다. 고령신도 그룹은 내부시 설의 '승강기 설치(3.73)'를 가장 중요한 요소로 인식하고 있다. 구체적으로 중요도가 높다고 인식하는 상위 10 개의 항목을 살펴보면 고령신도의 경우 기타시설의 소 그룹실의 설치기준에 대해 중요하다는 인식이 6 개 항목으로 가장 높 게 나타난다. 기타시설에 속하는 예배당에 관한 1 개 항목을 중요하다고 인식하고 있으며, 매개시설인 접근로 1 개, 그리 고 내부시설인 출입구의 2 개 항목을 중요하다고 인식하고 있다. 한편, 기능적 속성 외에 형태적 속성 (2항목)과 소재 적 속성(2항목)을 갖는 항목에 대한 중요성 인식은 유사한 것으로 나타난다(Table 11).

[Table 11] Perception of the aged believer group(above 10)

\begin{tabular}{|c|c|c|c|c|}
\hline Aged Believer & Score & Facilit & & \\
\hline Installation of elevator & 3.73 & Elevator & Inner & \\
\hline $\begin{array}{l}\text { Floor materials for easy } \\
\text { cleaning }\end{array}$ & 3.71 & $\begin{array}{l}\text { Small group } \\
\text { meeting room }\end{array}$ & Other & (0) \\
\hline Pedestrian-only access road & 3.70 & Access road & Interm. & \\
\hline $\begin{array}{l}\text { Gloss-less \& nonslip floor } \\
\text { Big-size light switch }\end{array}$ & $\begin{array}{l}3.68 \\
3.68\end{array}$ & \begin{tabular}{|l|} 
Small group \\
meeting room \\
Small group \\
meeting room \\
\end{tabular} & $\begin{array}{l}\text { Other } \\
\text { Other }\end{array}$ & () \\
\hline Storage & 3.66 & $\begin{array}{l}\text { Small group } \\
\text { meeting room }\end{array}$ & Other & \\
\hline $\begin{array}{l}\text { Screen size for the elderly with } \\
\text { defective vision } \\
\text { Height gap between main } \\
\text { entrance \& passage under } 20 \mathrm{~mm}\end{array}$ & \begin{tabular}{|l|}
3.65 \\
3.65
\end{tabular} & $\begin{array}{l}\text { Chapel } \\
\text { Main } \\
\text { entrance }\end{array}$ & Other & 0 \\
\hline $\begin{array}{l}\text { Change of the intensity of } \\
\text { illumination between adjacent } \\
\text { rooms } \\
\text { Lighting fixtures for clearly } \\
\text { differentiating colors }\end{array}$ & 3.58 & $\begin{array}{l}\text { Small group } \\
\text { meeting room } \\
\text { Small group } \\
\text { meeting room }\end{array}$ & Other & \\
\hline
\end{tabular}

o Form factor; () Material factor 
담임목사 그룹은 기타시설에 속하는 소그룹실의 '쉽게 청소되는 바닥재질의 사용(3.95)'을 가장 중요한 설치기준 으로 인식하고 있다. 담임목사 그룹은 기타시설의 소 그룹 실에 관한 1 개 항목, 매개시설인 접근로에 대해 3 개 항목, 내부시설 4 개 항목, 그리고 위생시설 2 개 항목을 중요설치 기준으로 인식하고 있다. 담임목사 그룹은 소재적 속성 (3 항목)을 갖는 항목이 형태적 속성(1항목)을 갖는 항목보다 중요하다는 인식을 보이고 있다(Table 12).

마지막으로 전문가 그룹은 매개시설에 속하는 접근로의 설치 기준 중에서 '차도와 분리된 보행안전 통로(4.88)'를

[Table 12] Perception of paster group(above 10)

\begin{tabular}{|c|c|c|c|c|}
\hline Pastor & Score & \multicolumn{3}{|c|}{ Facilities } \\
\hline $\begin{array}{l}\text { Floor materials for easy } \\
\text { cleaning }\end{array}$ & 3.95 & $\begin{array}{l}\text { Small group } \\
\text { meeting room }\end{array}$ & Other & (2) \\
\hline $\begin{array}{l}\text { Over } 3 \text { seconds of opening } \\
\& \text { closing }\end{array}$ & 3.89 & Main ent. & Inner & \\
\hline $\begin{array}{l}\text { Sign of the elderly only } \\
\text { Safety rails on both sides } \\
\text { Inner space }(1400 \times 1400 \mathrm{~mm})\end{array}$ & $\begin{array}{l}3.86 \\
3.86 \\
3.86\end{array}$ & $\begin{array}{l}\text { Parking } \\
\text { Stair } \\
\text { Toilet }\end{array}$ & \begin{tabular}{|c|} 
Interm. \\
Inner \\
Sanit. \\
\end{tabular} & ○ \\
\hline $\begin{array}{l}\text { Safety rail on corridor wall } \\
\text { Footlights on corners and } \\
\text { parts of changing level }\end{array}$ & $\begin{array}{l}3.84 \\
3.84\end{array}$ & $\begin{array}{l}\text { Corridor } \\
\text { Corridor }\end{array}$ & $\begin{array}{l}\text { Inner } \\
\text { Inner }\end{array}$ & \\
\hline Flat \& nonslip floor & 3.79 & Toilet & Sanit. & (2) \\
\hline $\begin{array}{l}\text { Pedestrian-only access } \\
\text { road }\end{array}$ & 3.77 & Access road & Interm. & \\
\hline Flat \& nonslip floor & 3.75 & Access road & Interm. & () \\
\hline
\end{tabular}

o Form factor; () Material factor

[Table 13] Perception of expert group(above 10)

\begin{tabular}{|c|c|c|c|c|}
\hline Expert & Score & \multicolumn{3}{|c|}{ Facilities } \\
\hline $\begin{array}{l}\text { Pedestrian-only access } \\
\text { road }\end{array}$ & 4.88 & Access road & Interm. & \\
\hline Cut-off of rail in the middle & 4.75 & Stair & Inner & \\
\hline Flat \& nonslip floor & 4.69 & Toilet & Sanit. & () \\
\hline $\begin{array}{l}\text { Closed location to main } \\
\text { entrance and passage }\end{array}$ & 4.60 & Elevator & Inner & \\
\hline $\begin{array}{l}\text { Ambient and bright lighting } \\
\text { fixtures }\end{array}$ & 4.53 & $\begin{array}{l}\text { Small group } \\
\text { meeting } \\
\text { room }\end{array}$ & Other & \\
\hline $\begin{array}{l}\text { Ramp with slope under } 1 / 18 \\
\text { (1/12 in necessary) }\end{array}$ & 4.50 & Access road & Interm & o \\
\hline Flat \& nonslip floor & 4.50 & Access road & Interm & () \\
\hline $\begin{array}{l}\text { Over } 3 \text { seconds of opening } \\
\& \text { closing }\end{array}$ & 4.50 & Main ent. & & \\
\hline Flat \& nonslip floor & 4.50 & Corridor & Interm & () \\
\hline Gloss-less \& nonslip floor & 4.50 & $\begin{array}{l}\text { Small group } \\
\text { meeting } \\
\text { room }\end{array}$ & Interm & (0) \\
\hline
\end{tabular}

o Form factor; () Material factor
가장 중요한 요소로 인식하고 있다. 전문가 그룹은 기타시 설의 소 그룹실 2 개 항목, 매개시설의 접근로 3 개 항목, 내 부시설 4 개 항목, 그리고 위생시설 1 개 항목을 중요 설치기 준으로 인식하고 있다. 또한 소재적 요소(4항목)를 형태적 요소(1항목)보다 더욱 중요하게 인식하고 있다(Table 13).

2) Non-Significant Convenience Facilities

반면에 가장 중요하지 않은 설치기준에 대한 인식 역시 주체별로 상이한 것으로 파악된다. 고령신도는 내부시설의 승강기 설치기준 중에서 '내부에 고령자가 잠시 숼 수 있는 접이식 의자 설치(2.33)'를 가장 중요하지 않은 것으로 인 식하고 있다. 구체적으로 시설 유형별 인식을 살펴보면, 편 의시설의 설치기준 중 내부시설의 9개 항목과 기타시설의 2 개 항목에 대해 중요하지 않다는 의견을 표명하고 있다. 항목의 속성으로 파악해 보면, 형태적 속성 (3항목)을 갖는 항목을 소재적 속성(2항목)을 갖는 항목보다 중요하지 않 은 것으로 인식하고 있다(Table 14).

[Table 14] Perception of the aged believer group(below 10)

\begin{tabular}{|c|c|c|c|c|}
\hline Aged Believer & Score & \multicolumn{3}{|c|}{ Facilities } \\
\hline $\begin{array}{l}\text { Folding chair for the elderly } \\
\text { resting in elevator }\end{array}$ & 2.33 & Elevator & Inner & \\
\hline $\begin{array}{l}\text { Footlights on corners and } \\
\text { parts of changing level }\end{array}$ & 2.69 & Corridor & Inner & \\
\hline Seats for the elderly & 2.73 & Chapel & Other & \\
\hline $\begin{array}{l}\text { Preference sliding door to } \\
\text { hinged door }\end{array}$ & 2.93 & Entrance & Inner & o \\
\hline Safety rail on corridor wall & 3.07 & Corridor & Inner & \\
\hline Riser height(under 180mm) & 3.09 & Stair & Inner & O \\
\hline $\begin{array}{l}\text { Cut-off of rail in the middle } \\
\text { Flat and nonslip floor }\end{array}$ & $\begin{array}{l}3.11 \\
3.11\end{array}$ & $\begin{array}{l}\text { Stair } \\
\text { Stair }\end{array}$ & $\begin{array}{l}\text { Inner } \\
\text { Inner }\end{array}$ & (2) \\
\hline $\begin{array}{l}\text { Finishing materials at the } \\
\text { beginning and ending point } \\
\text { of stair for warning } \\
\text { Horizontal extension of } \\
\text { safety rail up to } 300 \mathrm{~mm} \\
\text { Floor heating for the elderly } \\
\text { with knee--ioints problem }\end{array}$ & $\begin{array}{l}3.12 \\
3.12\end{array}$ & $\begin{array}{l}\text { Stair } \\
\text { Chapel }\end{array}$ & $\begin{array}{l}\text { Inner } \\
\text { Other }\end{array}$ & (2) \\
\hline
\end{tabular}

o Form factor; () Material factor

담임목사 그룹은 기타시설의 소 그룹실 설치기준 중에 서 '색 인식이 잘되는 조명기구(2.67)'를 가장 중요하지 않 은 항목으로 인식하고 있다. 시설의 유형별로 담임목사 그 룹의 인식을 살펴보면, 기타시설의 6개 항목, 내부시설의 3 개 항목, 그리고 매개시설의 1 개 항목에 대해 중요하지 않 다고 인식하고 있다. 또한 형태적 요소(2항목)가 소재적 요 소(1항목)보다 중요하지 않다는 인식을 보이고 있다(Table 15). 
[Table 15] Perception of paster group(below 10)

\begin{tabular}{l|c|l|l|l}
\hline \multicolumn{1}{c|}{ Pastor } & Score & \multicolumn{3}{c}{ Facilities } \\
\hline $\begin{array}{l}\text { Lighting fixtures for clearly } \\
\text { differentiating colors }\end{array}$ & 2.67 & $\begin{array}{l}\text { Small group } \\
\text { meeting } \\
\text { room }\end{array}$ & Other & \\
\hline $\begin{array}{l}\text { Adhesion of color strip in } \\
\text { case of a clear glass door }\end{array}$ & 2.73 & Main ent. & Inner & O \\
\hline Seats for the elderly & 2.86 & Chapel & Other & \\
\hline $\begin{array}{l}\text { Preference sliding door to } \\
\text { hinged door }\end{array}$ & 2.91 & Entrance & Inner & 0 \\
\hline $\begin{array}{l}\text { Floor heating for the elderly } \\
\text { with knee-joints problem }\end{array}$ & 3.09 & Chapel & Other & \\
\hline $\begin{array}{l}\text { Parking lots-the elderly } \\
\text { only }\end{array}$ & 3.18 & Parking & Interm. & \\
\hline Installation of elevator & 3.21 & Elevator & Inner & \\
\hline Hearing aid equipment & 3.23 & Chapel & Other & \\
\hline Big-size light switch & 3.31 & $\begin{array}{l}\text { Small group } \\
\text { meeting } \\
\text { room }\end{array}$ & Other & 0 \\
\hline Storage space & 3.33 & $\begin{array}{l}\text { Small group } \\
\text { meeting } \\
\text { room }\end{array}$ & Other & \\
\hline
\end{tabular}

o Form factor; () Material factor

[Table 16] Perception of expert group(below 10)

\begin{tabular}{|c|c|c|c|c|}
\hline Expert & Score & \multicolumn{3}{|c|}{ Facilities } \\
\hline Seats for the elderly & 3.25 & Chapel & Other & \\
\hline Toilet for the elderly & 3.40 & Toilet & Sanit. & \\
\hline $\begin{array}{l}\text { Flat and nonslip floor } \\
\text { Change of the intensity } \\
\text { of illumination between } \\
\text { adjacent rooms }\end{array}$ & $\begin{array}{l}3.50 \\
3.50\end{array}$ & $\begin{array}{l}\text { Stair } \\
\text { Small group } \\
\text { meeting } \\
\text { room }\end{array}$ & $\begin{array}{l}\text { Inner } \\
\text { Other }\end{array}$ & () \\
\hline $\begin{array}{l}\text { Finishing materials to } \\
\text { discern colors of dark wall } \\
\text { and floor }\end{array}$ & 3.56 & $\begin{array}{l}\text { Small group } \\
\text { meeting } \\
\text { room }\end{array}$ & Other & () \\
\hline $\begin{array}{l}\text { Hearing aid equipment } \\
\text { Floor heating for the elderly } \\
\text { with knee-joints problem }\end{array}$ & $\begin{array}{l}3.57 \\
3.57\end{array}$ & $\begin{array}{l}\text { Chapel } \\
\text { Chapel }\end{array}$ & $\begin{array}{l}\text { Other } \\
\text { Other }\end{array}$ & \\
\hline $\begin{array}{l}\text { Safety rail on corridor wall } \\
\text { Horizontal extension of } \\
\text { safety rail up to } 300 \mathrm{~mm}\end{array}$ & $\begin{array}{l}3.63 \\
3.63\end{array}$ & $\begin{array}{l}\text { Corridor } \\
\text { Stair }\end{array}$ & $\begin{array}{l}\text { Inner } \\
\text { Inner }\end{array}$ & $\mathrm{O}$ \\
\hline $\begin{array}{l}\text { Footlights on corners and } \\
\text { parts of changing level } \\
\text { Folding chair for the elderly } \\
\text { resting in elevator }\end{array}$ & $\begin{array}{l}3.67 \\
3.67\end{array}$ & $\begin{array}{l}\text { Corridor } \\
\text { Elevator }\end{array}$ & $\begin{array}{l}\text { Inner } \\
\text { Inner }\end{array}$ & \\
\hline $\begin{array}{l}\text { Wall plug location of } 900- \\
1200 \mathrm{~mm} \text { over the floor }\end{array}$ & 3.67 & $\begin{array}{l}\text { Small group } \\
\text { meeting } \\
\text { room }\end{array}$ & Other & $\mathrm{O}$ \\
\hline
\end{tabular}

o Form factor; () Material factor

그리고 전문가 그룹은 기타시설의 예배당에 '고령자 전 용좌석 설치 (3.25)'를 가장 중요하지 않다고 인식하고 있
다. 시설유형별로 보면, 기타시설 6개 항목, 위생시설 1 개 항목, 그리고 내부시설 5 개 항목에 대해 설치기준이 중요 하지 않다고 인식하고 있다. 또한 전문가 그룹은 항목의 속 성별 중요성에 대해서 형태적 요소(2항목)와 소재적 요소 (2항목) 간의 상대적 중요도에 유사한 인식을 보이고 있다 (Table 16).

이러한 설치 기준의 중요도에 대한 인식의 차이는 사용 의 빈도나 교회에서 가장 많이 접하게 되는 공간에 대한 접 촉의 정도에 의해 발생하는 것으로 보인다. 고령신도의 경 우, 교회에 왔을 때 예배당 이용과 소 그룹실 등에서 이루어 지는 친교활동 등에 의해 획득한 공간의 친숙성 때문에 편 의시설의 적절성을 평가할 수 있는 경험치가 높기 때문일 것이다. 담임목사는 시무하는 교회의 고령신도를 위해 편의 성을 개선하기 위한 목적으로 모든 시설 유형에 걸쳐 개선 점을 인식하고 있다. 건축이나 인테리어디자인 전문가들은 고령자들의 이용 편의성을 증진시키기 위한 구체적 방안에 대한 식견에 의해 전체적으로 모든 부분에 걸쳐 중요성을 인정하고 있다. 담임목사 그룹과 전문가 그룹은 매개시설과 내부시설의 편의시설 설치 기준의 준수를 고령신도의 편의 성 개선을 위해 더욱 중요한 것으로 인식하고 있다.

\section{Conclusion}

인구 고령화에 의해 증가하는 교회의 고령신도들의 편의 와 안전을 증진시키기 위한 시설개선 사업에 대한 관심이 증가하고 있으나, 고령자의 편의시설 설치기준에 대한 경 험적 연구가 부족하다는 문제의식에 의해 시작된 본 연구 는 고령신도, 담임목사, 그리고 건축 및 인테리어 전문가 그 룹을 대상으로 하여 설문조사를 실시하였다. 고령신도 그룹 은 기타시설 중 특히 소 그룹실과 관련된 설치기준의 중요 성을 높게 인식하고 있다. 담임목사 그룹은 각 시설유형에 걸쳐 설치기준의 중요성을 균형 있게 인식하고 있으나, 특 히 매개시설과 내부시설의 설치기준을 더욱 중요하게 생각 하고 있다. 전문가 그룹 역시 담임목사 그룹과 동일하게 각 시설유형에 걸쳐 시설기준의 중요성을 인식하고 있으나, 그 중에서도 매개시설과 내부시설의 설치 기준을 중요하게 인 식하고 있다. 한편 설치 기준 항목의 속성에 대한 인식을 형 태, 소재, 그리고 기능으로 대별하여 살펴보면, 고령신도 그 룹은 소재 요소보다 형태 요소를 더욱 중요한 것으로 인식 하고 있으나 담임목사 그룹과 전문가 그룹은 소재 요소를 형태요소보다 더욱 중요한 것으로 인식하는 경향이 발견된 다. 따라서 교회의 고령신도를 위한 편의시설 개선 사업과 관련된 주체들의 입장에 따라 편의시설 설치 기준의 적절 성에 대한 견해의 차이는 고령신도를 위한 교회 개선사업 의 방향과 범위를 설정하는 데에 다음과 같은 중요한 시사 점을 제공한다. 즉, 교회 개선사업에 참여하는 다양한 구성 
원들은 공간 사용의 정도나 관점의 차이 등에 의해 인식하 는 설치기준의 중요도에 대한 인식이 상이하기 때문에, 제 한된 예산의 범위 내에서 개선 사업을 진행해야 하는 경우 에는 수혜자의 관심정도를 파악하여 우선순위를 설정하여 야 할 것이다.

또한 연구결과의 타당성을 증가시키기 위해서는 교회시 설 사용자들의 일반적 특성에 대한 보다 세밀한 비교분석 이 이루어져야 하나, 본 연구에서는 자동차 이용 현황이나 활동성 제약요인과 같은 고령신도의 신체적 특성과 같은 항목에 대해서는 조사되지 않아 보편적 일반화 획득에는 제약요소로 작용하리라 판단된다. 연구의 범위를 구체적으 로 세분화하여 한정하고 고령신도의 일반적 특성을 포섭하 여 연구의 타당도를 더욱 증대시키는 후속연구를 기대한다.

\section{References}

1. Chai, Cuoul Gyun, 2011, A study on the medical environmental factor and distinction of medical facilities for the elderly in Berlin, Korea Institute of Healthcare Architecture Journal, Vol.17, No.1, pp.15-22.

2. Ju, Ye Jin; Lee, Yoon Hie, 2006, relationship-process methodology proposal for emerging a local community as a diaspora church, 2006 Fall Conference Proceedings, Vol.26, No.1, pp.409-414.

3. Kim, Duk-Su, 2011, Research trends of healthcare and welfare facilities-An assessment of Korea Institute of Healthcare Architecture Journal, Vol.17, No.2, pp.17-25.

4. Kim, Suntae, 2012, A study on the characteristics of residents' spatial use of common space in care house with residential units in Japan, Korea Institute of Healthcare Architecture Journal, Vol.18. No.3, pp.19-28.

5. Kim, Young-Ki; Cho, Jong-Soo, 2006, A study on multi functional church planning based on local culture, 2006 Fall Conference Proceedings, Vol.26, No.1, pp.21-24.

6. Lee, Hee-Jun, 2011, A study on the recent characteristics of Protestant church architecture's worship space in Korea, Journal of Korean Institute of Architecture, Vol.27, No.12, pp.137-144.

7. Lee, Hee-Jun; Kim, Jeong-IL; Yoon, In-Suk, 2009, A study on the characteristics of changes and the plan type of Protestant church architecture's worship space in Korea, Journal of Korean Institute of Architecture, Vol.25, No.5, pp.31-38.

8. Lee, Jong-Hee; Kim, Duk-Su, 2012, Usability evaluation of churches' convenience facilities for the elderly, JKorea Institute of Healthcare Architecture Journal, Vol.18, No.4, pp.29-38.

9. Lee, Kyoo-Il; Kang, Byoung-Keun, 2011, A study on the improvement direction of barrier-free certification evaluation items, Korea Institute of Healthcare Architecture Journal, Vol.17, No.4, pp.25-37.

10. Lee, Yang Keong; Lee, Ho Chin, 1995, A study on the transitional space classified by each type for church architecture, 1995 Spring Conference Proceedings, Vol.15, No.1, pp.159-162.

11. Lee, Yong-Taeg; Park, Han-Kyu, 2005, A study on the accessibility for the disabled people to church buildings, 2005 Proceedings, Vol.25, No.1, pp.191-194.

12. Moon, Changho, 2011, Elements and application of smarthome concept for older adults in USA, Korea Institute of Healthcare Architecture Journal, Vol.17, No.4, pp.7-14.

13. Seong, Kichang, 2012, A study on activation of sports activities for the disabled in public sports centers, Korea Institute of Healthcare Architecture Journal, Vol.18, No.4, pp.89-97.

14. Tak, Young Ran; An Ji Yeon; Jung, So Young, 2012, A study on correlation between therapeutic outdoor environments and health outcomes in geriatric hospital, Korea Institute of Healthcare Architecture Journal, Vol.18, No.1, pp.45-52.

15. Woo, Seung-Pyo; Lee, Young-Soo, 2002, The planning of a urban church as a social cultural facility, 2002 Fall Conference Proceedings, Vol.22, No.2, pp.307-310.

16. Yoon, Hee-Cheol; Song, Jong-Suk, 1994, A field study on the social function \& spatial use of church in Seoul metropolitan area(II), Journal of Korean Institute of Architecture, Vol., 10, No.2, pp.13-24.

17. You, Jong-Ok; Park, Jae-Seung, 2011, A study on proposal of facility standard by research of safety accidents at elderly housing welfare facility, Korea Institute of Healthcare Architecture Journal, Vol.17, No.2, pp.7-16.

18. Yun, Wooyong; Chai, Choul Gyun, 2011, A study on the architectural guideline of the patient room in the geriatric medical center, Korea Institute of Healthcare Architecture Journal, Vol.17, No.3, pp.17-26.

19. Yun, Youngil; Cho, Juyoung; Lee, Hyowon, The study on the analysis of useful daylight illuminance in care facilities, Korea Institute of Healthcare Architecture Journal, Vol.17, No.1, pp.33-40.

접수 : 2012년 12월 31일 1차 심사 완료 : 2013년 1월 16일 게재확정일자 : 2013년 1월 16일 3인 익명 심사 필 